\author{
국내 TMR의 입자도에 관한 조사 연구 \\ 기광석*.김현섭*.정하연*.이현준*.안병석*.김준식*.강수원*·김용국**.하종규*** \\ 축산기술연구소*, 충남대학교**, 서울대학교***
}

\title{
The Survey of Particle Size of Total Mixed Ration in Korea
}

\author{
K. S. Ki*, H. S. Kim*, H. Y. Jeong*, H. J. Lee*, B. S. Ahn*, J. S. Kim*, S. W. Kwang*, \\ Y. K. Kim** and J. K. Ha*** \\ National Livestock Research Institute*, Chungnam National University**, \\ Seoul National University***
}

\begin{abstract}
This study was carried out to survey operation system of self-making TMR and particle size of self-making and commercial TMR, then to compare TMR particle size recommended by Penn State Particle Size Separator. Daily mixing time in self-making TMR averaged 48.6 $\pm 28.0 \mathrm{~min}$., 2 augar type of mixer was most by $55.5 \%$ and daily 2 times of mixing in summer and other season was 44.4 and $22.2 \%$, respectively. Percentage of residual feed in upper sieve(19mm diameter), middle sieve(8 to $18 \mathrm{~mm}$ diameter) and lower pen was $21.5 \sim \sim \sim \sim 1.4 \%$, respectively, at self-making TMR mixer. Percentage of particle sizes of more than $19 \mathrm{~mm}$ in self-making and commercial TMR was 24.9 \pm 1.4 and $26.2 \pm 1.7 \%$, that of $8-10 \mathrm{~mm} 22.8 \pm 1.0$ and $12.8 \pm 1.2$ and that of less than $8 \mathrm{~mm} 52.3 \pm 1.7$ and $61.0 \pm 1.5$, respectively, which in particle length of $8 \sim 3 \mathrm{~mm}$ in self-making and commercial TMR was lower by 82.6 and $100 \%$ compared to that recommended by Penn State particle separator, respectively. Especially there was not particle length of more than $19 \mathrm{~mm}$ in commercial TMR at all. It is necessary to check the number of cows ruminating in a farm in order to estimate the particle size of TMR; it is recommended to change the TMR mixing time or the TMR formulae if the proportion of ruminating cows in a farm is less than $40 \%$.
\end{abstract}

(Key words : TMR, Particle size, Survey, Mixer, Mixing time)

$$
\mathrm{I} \text { 서 론 }
$$

Smith 등(1983)은 젖소들의 능력이 점점 고 능력화 됨에 따라 고에너지를 요구하게 되고, 이에 따라 젖소 사료에 농후사료 비율이 점차 높아지게 된다고 하였다. 더구나 국내 낙농가 에서 자급조사료가 절대적으로 부족한 현실이 며, 조사료의 대부분은 볏짚이나 수입건초에 의존하고 있는 실정이다.
젖소는 반추가축이므로 다른 영양소 외에 섬 유질을 요구한다(NRC, 1989). Sudweeks 등(1981) 은 만약 소들이 필요로 하는 최소 섬유소 요구 량을 충족시키지 못했을 때, 소들은 총 건물소 화율의 감소, 유지율 저하, 제 4 위 전위, 반추위 부전 각화증의 발병 증가, 제엽염(啼葉炎 과 산증, 과비증후군 등을 나타낸다고 하였다.

또한, 화학적 성분분석에 의한 조사료 추천 요구량이 충족되었다해도 급여 당시 조사료의

Corresponding author : K. S. Ki, National Livestock Research Institute, R. D. A, 330-801, Korea. E-mail : kiks386@ rda.go.kr, Tel : 041-580-3334, Fax : 041-580-3385. 
물리성, 특히 조사료의 길이가 적정 반추위 환 경유지에 매우 중요한 역할을 한다. 즉, 아주 곱게 분쇄된 조사료로서 충분한 $\mathrm{NDF}$ 를 먹은 소들도 사료중 섬유소 부족에 의한 것 같은 대 사성 질병들을 나타낼 수 있다고 하였다(Fahey 등, 1988; Weston 등, 1984). Woodford와 Murphy(1988)은 적절한 조사료 입자길이는 적절한 반추위 기능을 위해 필수적이며, 조사료 입자 크기가 작으면 저작시간 감소, 반추위 산도 저 하 등의 현상을 보인다고 하였다. Sudweeks 등 (1981)은 평균 입자 크기, 건물 그리고 $\mathrm{NDF}$ 를 사용하여 사료의 저작시간을 판정하기 위하여 조사료 가치 지수를 개발하였는데, 조사료 입 자 길이가 불충분 할 때, 소들은 저작시간이 감소하고, 생산된 침의 양이 감소하므로 반추 위 중화가 필요하다고 하였다. Grant 등(1990) 에 의하면, 곱게 분쇄된 사료를 먹은 소들은 조악한 사료를 먹은 소들보다 반추시간이 2.5 시간 적었다고 하였다. 불충분한 입자 크기는 반추위내 acetic acid와 propionic acid 비율 감 소, $\mathrm{pH}$ 저하로 유지율 저하를 야기한다고 알려 져 있다(Grant 등, 1990; Santini, 1983; Shaver, 1990; Woodford 등, 1986).

반추위내 $\mathrm{pH}$ 가 6이하로 떨어지면, cellulose 분해 미생물의 성장은 저하되고, acetic acid대 propionic acid의 비율이 감소함으로서 propionic acid를 생성하는 미생물이 증가한다고 알려져 있다(Grant 등, 1990). 조사료 입자크기 감소는 건물섭취량 증가, 소화율 감소, 반추위내 고형 물 지체시간 감소를 나타낸다고 하였다(Jaster 등, 1983; Martz 등, 1986; Uden, 1987). 반추위 내로 들어가는 조사료 입자 크기가 적으면 초 기 저작과 삼킨 후에 입자가 더욱 작아져 빠른 속도로 반추위를 떠나게 되며, 이러한 결과 건 물 섭취량은 증가하고 반추위 건물의 하부장기 로 이행율도 증가하지만(Fashey 등, 1988; Jaster 등, 1983; Martz 등, 1986; Weston 등, 1984), 미 생물 소화에 의한 반추위내 체류하는 시간이 적게 되여, 특히 조섬유 소화율이 감소한다 (Uden, 1987).

따라서 본 연구는 자가 $\mathrm{TMR}$ 농가의 $\mathrm{TMR}$ 배 합기 운영실태와 Penn State Particle Size
Separator를 이용하여 국내에서 생산 이용되고 있는 TMR을 대상으로 TMR 배합소에서 생산 되는 유통 $\mathrm{TMR}$ 과 농가에서 직접 제조하여 이 용하는 자가 $\mathrm{TMR}$ 의 입자도를 분석 비교하여 국내 TMR의 적정 입자도를 제시하기 위한 기 초자료로 활용하기 위해 수행하였다.

\section{재료 및 방법}

\section{1. 공시재료}

본 시험을 위해 국내에서 생산 판매되고 있 는 TMR 배합소 샘플 20점과 자가제조 농가 $\mathrm{TMR}$ 샘플 20점을 공시하였다.

\section{2. 시험기간 및 장소}

본 시험은 2002년 3월에서 10월까지 경기도 와 충청도에서 수집한 TMR 샘플을 축산기술 연구소에서 분석하였다.

\section{3. 시험설계}

본 시험은 국내에서 생산 이용되고 있는 $\mathrm{TMR}$ 의 입자도를 측정하기 위하여 $\mathrm{TMR}$ 배합 소 샘플 20점과 자가 $\mathrm{TMR}$ 샘플 20점을 각각 2반복씩 미국 Pennsylvania 대학에서 개발한 Penn State Particle Size Separator로 입자도를 측정하였다.

\section{4. 조사항목 및 방법}

(1) 자가 TMR 농가의 배합기 가동시간 및 배합회수

자가 TMR 농가의 배합기 가동시간, 배합회 수 등은 조사표를 만들어 직접방문하여 조사하 였다.

(2) 입자도 측정

Penn State Particle Size Separator를 이용하여

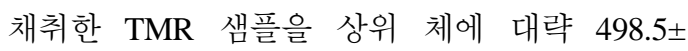
$142.7 \mathrm{~g}$ 을 놓은 다음, 평평한 바닥에 놓고 체를 
Table 1. Time for mixing one batch for self-making $\mathrm{TMR}^{1}$

\begin{tabular}{|c|c|c|c|c|}
\hline $\begin{array}{l}\text { Mixing during raw } \\
\text { materials input(A) }\end{array}$ & \multicolumn{2}{|c|}{$\begin{array}{l}\text { Mixing after input } \\
\text { (B) }\end{array}$} & \multicolumn{2}{|r|}{$\begin{array}{l}\text { Total mixing } \\
(\mathrm{A}+\mathrm{B})\end{array}$} \\
\hline Duration (minute) & \multicolumn{2}{|l|}{$15.2 \pm 15.9$} & \multicolumn{2}{|r|}{$48.6 \pm 28.0$} \\
\hline \multirow{4}{*}{$\begin{array}{l}{ }^{1} \text { Mean } \pm \text { S.D. } \\
\text { 한 방향으로 } 5 \text { 회씩 흔들었다. 한 방향으로 } 5 \text { 회 } \\
\text { 흔든 후 } 1 / 4 \text { 씩 돌려가면서 총 } 40 \text { 회가 되게 흔 } \\
\text { 든 다음 각 체에 남아 있는 양의 무게를 달았 } \\
\text { 다. Penn State Particle Size Separator는 } 3 \text { 단계 } \\
\text { 체로 구성되어 있으며, 상위 체의 mesh 크기는 } \\
\text { 직경이 } 19 \mathrm{~mm} \text { 이상, 중간 체의 mesh 크기는 직 } \\
\text { 경이 } 8 \mathrm{~mm} \text { 이상 } 7 \mathrm{~mm} \text { 미만 그리고 바닥 체는 } \\
\text { mesh가 없는 pan으로 구성되어 있다. }\end{array}$} & \multicolumn{4}{|c|}{$\begin{array}{l}\text { Table 2. The seasonal variation in the number } \\
\text { of batch for self-making TMR } \\
\text { (unit : \%) }\end{array}$} \\
\hline & Item & & Summer & Other seasons \\
\hline & $\begin{array}{l}\text { Mixing frequency } \\
\text { (time/day) }\end{array}$ & 2 & $\begin{array}{l}55.6 \\
44.4\end{array}$ & 77.8 \\
\hline & Total & & 100 & 100 \\
\hline
\end{tabular}

\section{5. 통계분석}

본 시험의 모든 성적은 SAS package(Cary, NC., 1997)를 이용하여 통계분석 하였으며, 각 처리 평균간 차이에 대하여 DMRT(Duncan, 1955) 방법을 이용하여 유의성 검정을 하였다.

\section{III 결과 및 고찰}

1. 자가 TMR농가의 배합기 운용시간 및 1 일 배합회수

Table 1에서 보듯이 자가 TMR 농가의 배합 기 운용시간을 보면, 최초 사료 투입시부터 마 지막 원료사료를 투입할 때까지 배합기 가동시 간은 33.3 \pm 23.6 분이었고, 마지막 원료를 투입 하고 난 이후 최종 배합 종료시까지 약 $15.2 \pm$ 15.9 분을 더 가동하여 자가 TMR 농가의 1 일 총 배합시간은 평균 48.6 \pm 28.0 분으로 조사되었 다. 이는 배합기의 종류와 배합되는 원료사료 의 종류 등에 따라 배합에 소요되는 시간이 다 르겠지만 일반적으로 알려져 있는 마지막 원료 사료 투입 후 5분 이상 가동시 조사료 입자도 가 감소할 수 있다는 보고(J.G.Linn, 1995) 보다 더 많은 시간을 가동하는 것으로 나타났다. 또 한 1 일 배합기 운용회수(Table2)는 계절별로 차 이가 있었는데, 여름철에는 1 일 1 회 배합하는

Table 3. The types of TMR mixer for self-making TMR

\begin{tabular}{|c|c|c|c|c|}
\hline Item & 2 Augar & 3 Augar & 4 Augar & Vertical \\
\hline $\begin{array}{c}\text { Type of mixer } \\
\text { (\%) }\end{array}$ & 55.5 & - & 27.8 & 16.7 \\
\hline
\end{tabular}

농가는 $55.6 \%$ 였고, 1 일 2회 배합하는 농가는 $44.4 \%$ 였으며 다른 계절에는 1 일 2회 배합하는 농가는 $22.2 \%$, 그리고 1 일 1 회 배합하는 농가 는 $77.8 \%$ 로 나타났다. 이는 여름철 고온으로 인한 사료의 변질을 우려한 낙농가의 선택 때 문이라 생각된다. 또한, 위에 언급한바와 같이 일부 낙농가에서는 여름은 물론 계절에 상관없 이 신선한 사료의 급여를 위해 연중 1 일 2회 혼합하여 급여하는 낙농가도 조사농가의 $22.2 \%$ 가 되었다.

Table 3은 자가 TMR 농가에 주로 많이 보급 되어 이용하고 있는 배합기 날 형태를 조사한 성적으로 2오거, 4오거 형태로 55.7 및 27.3\% 였으며 최근에 개발된 수직형 오거도 $16.7 \%$ 를 사용하고 있었다.

\section{2. 자가 TMR 농가의 배합시간별 입자도}

Table 4는 배합기 가동시간에 따른 입자도 분포를 나타낸 성적으로서, 조사된 농가의 자 가 TMR 배합기 가동시간별로 입자크기에 따 
른 상위, 중간 및 바닥 체에 남은 사료비율은 15 )분 가동한 농가의 경우 각각 $23.1 \pm 2.0$, $22.9 \pm 1.4, \quad 54.0 \pm 1.9 \%$ 였으며, 31 j분 가동 농가에서는 $\quad 22.6 \pm 3.8, \quad 16.0 \pm 2.6, \quad 61.4 \pm 3.5 \%$ 로 나타났다. 배합기 가동시간이 46 )분인 농가 에서는 $25.6 \pm 2.4, \quad 19.4 \pm 1.7, \quad 55.0 \pm 2.2 \%$ 였으며, 60 분이상 가동 농가의 경우 $21.5 \pm 2.7,25.8 \pm$ $1.9,52.8 \pm 2.5 \%$ 으로 60 분 이상 가동한 농가에 서 사료의 길이가 8 $7 \mathrm{~mm}$ 의 비율이 가장 높 게 나타났다 $(\mathrm{P}<.05)$. 배합시간이 길어질수록 긴 건초 등 조사료가 절단되어 상위 체에 남아 있는 비율이 줄어들 것으로 생각되었으나 본 조사에서는 배합기 가동시간에 따른 입자도 감 소에 일정한 경향이 나타나지 않았다. 이는 농 가에서 사용하고 있는 배합기에 부착된 cutting 칼날의 마모정도가 다름으로 인한 차이와 입자 도를 고려하여 구입시 배합기에 부착된 칼날을 임의로 일부를 제거하거나 추가하였기 때문인 것으로 사료된다.

\section{3. 자가 TMR과 유통 TMR의 입자도 분포}

Table 5에서와 같이 자가 TMR과 시중에서 유통되고 있는 $\mathrm{TMR}$ 에 대하여 입자도를 조사 한 결과, 자가 $\mathrm{TMR}$ 과 유통 $\mathrm{TMR}$ 모두에서 상 위 체(mesh의 직경이 $19 \mathrm{~mm}$ 이상)에 남아 있는
비율은 각각 $24.9 \pm 1.4$ 및 $26.2 \pm 1.7 \%$ 였는데 이 비율은 Penn State Particle Size Separator(Jud Heinrichs, 1996)의 추천 비율인 6 \%이상 보 다 높게 나타났다. 그러나, 자가 $\mathrm{TMR}$ 과 유통 $\mathrm{TMR}$ 의 중간 체(mesh의 직경이 8 $\mathrm{Jmm}$ )에 남아 있는 비율은 각각 $22.8 \pm 1.0$ 및 $12.8 \pm$ $1.2 \%$ 으로 추천 비율인 30 \% 보다 적게 나 타났다. 바닥 체(mesh의 직경이 $8 \mathrm{~mm}$ 미만)에 남 아 있는 비율은 자가 TMR 및 유통 $\mathrm{TMR}$ 에서 각각 $52.3 \pm 1.7$ 및 $61.0 \pm 1.5 \%$ 로 추천 비율인 40 J\%를 비교하면 자가 $\mathrm{TMR}$ 은 추천된 범 위에 들었으나 유통 $\mathrm{TMR}$ 에서는 추천된 범위 를 벗어나는 것으로 조사되었다. 이러한 조사 결과를 다시 Table 6에서와 같이 추천된 적정 범위에 얼마나 포함되는지를 살펴본 결과, 자 가 $\mathrm{TMR}$ 은 추천 범위에 포함되는 비율은 상위 체, 중간 체, 바닥 체에서 각각 $4.4 \%, 17.4 \%$, $78.2 \%$ 으로 중간 체에 남아 있는 비율은 $82.6 \%$ 가 추천된 범위보다 낮았다. 반면에 유통 TMR 은 추천된 범위에 포함되는 비율은 상위 체, 중간 체, 바닥 체에서 각각 $47.1 \%, 0 \%, 52.9 \%$ 로 유통 $\mathrm{TMR}$ 은 중간 체에 남아 있는 비율은 $100 \%$ 가 추천된 범위보다 낮게 나타났다. 이와 같은 조사결과를 바탕으로 자가 및 유통 $\mathrm{TMR}$ 에 대한 평균 입자도를 비교한 결과를 Table 5에서 보면, 중간 체의 사료잔량 비율은 추천비율의

Table 4. Mean particle sizes as influenced by mixing times in self-making $\operatorname{TMR}^{1,2)} \quad$ (unit : \%)

\begin{tabular}{|c|c|c|c|c|}
\hline \multirow{2}{*}{ Item } & \multicolumn{4}{|c|}{ Mixing time(minute) } \\
\hline & $15 \sim)$ & $31 \sim j$ & $46 \sim)$ & $60<$ \\
\hline Upper sieve( $>19$ mm) & $23.1 \pm 2.0$ & $22.6 \pm 3.8$ & $25.6 \pm 2.4$ & $21.5 \pm 2.7$ \\
\hline Middle sieve $(8 \sim \Rightarrow \mathrm{mm})$ & $22.9 \pm 1.4^{\mathrm{ab}}$ & $16.0 \pm 2.6^{\mathrm{c}}$ & $19.4 \pm 1.7^{\mathrm{bc}}$ & $25.8 \pm 1.9^{\mathrm{a}}$ \\
\hline Bottom panl< $<8 \mathrm{~mm})$ & $54.0 \pm 1.9$ & $61.4 \pm 3.5$ & $55.0 \pm 2.2$ & $52.8 \pm 2.5$ \\
\hline
\end{tabular}

${ }^{1)}$ Mean \pm S.D.

${ }^{2)}$ Means with different superscripts are significantly different $(I<.05)$.

Table 5. Percentage of particle sizes by sieve diameter in self-making and commercial TMR

\begin{tabular}{lccc}
\hline \multicolumn{1}{c}{ Item } & $\begin{array}{c}\text { Upper sieve } \\
(>19 \mathrm{~mm})\end{array}$ & $\begin{array}{c}\text { Middle sieve } \\
(8 \sim 7 \mathrm{~mm})\end{array}$ & $\begin{array}{c}\text { Bottom pan } \\
(<8 \mathrm{~mm})\end{array}$ \\
\hline \hline Recommended TMR particle size(\%) & $6 \sim 2 \%$ or more & $30 \sim) \%$ & $40 \sim) \%$ \\
\hline Self-making TMR(\%) & $24.9 \pm 1.4$ & $22.8 \pm 1.0^{\mathrm{a}}$ & $52.3 \pm 1.7^{\mathrm{b}}$ \\
Commercial TMR(\%) & $26.2 \pm 1.7$ & $12.8 \pm 1.2^{\mathrm{b}}$ & $61.0 \pm 1.5^{\mathrm{a}}$ \\
\hline
\end{tabular}

${ }^{1)}$ Mean \pm S.D.

${ }^{2)}$ Means with different superscripts are significantly different within same column $(1<.05)$. 
Table 6. Percentage of self-making and commercial TMR particie size to recommended TMR particle size by sieves

\begin{tabular}{|c|c|c|c|}
\hline \multirow{2}{*}{ Item } & \multicolumn{3}{|c|}{ Recommended TMR particle size } \\
\hline & Below & Optimum & Over \\
\hline & $\cdots$ & $\cdots(\%) \cdot$ & ....... \\
\hline \multicolumn{4}{|l|}{ Self-making TMR } \\
\hline - upper sieve( $>19$ mm) & 13.0 & 4.4 & 82.6 \\
\hline - middle sieve $(8 \sim \quad \exists \mathrm{mm})$ & 82.6 & 17.4 & - \\
\hline - bottom panı $<8 \mathrm{~mm})$ & 4.4 & 78.2 & 17.4 \\
\hline \multicolumn{4}{|l|}{ Commercial TMR } \\
\hline - upper sieve( $>19 \mathrm{~mm})$ & - & 47.1 & 52.9 \\
\hline - middle sieve(8〜 $7 \mathrm{~mm})$ & 100 & - & - \\
\hline - bottom panı $<8 \mathrm{~mm})$ & - & 52.9 & 47.1 \\
\hline
\end{tabular}

범위를 모두 벗어나는 것으로 나타났으며, 특 히 유통 $\mathrm{TMR}$ 의 경우가 자가 TMR보다 그 비 율이 낮은 것으로 나타났다( $<$.01). 그리고 바 닥 체의 경우 반대로 유통 $\mathrm{TMR}$ 의 잔량 비율 이 자가 TMR의 비율보다 높게 나타났으며(I < $.01)$ 추천비율 범위의 상한값( $60 \%)$ 를 약간 벗 어나는 경향을 보였다. 즉 이는 중간 체에 남 이 있는 사료의 비율이 낮고 바닥 체에 남이 있는 비율이 높다는 것은 사료, 특히 조사료의 길이가 적정 추천 수준보다 짧다는 것을 의미 하며 이로 인하여 조사료의 물리성이 감소하여 반추에 의한 타액생산 감소로 반추위내 $\mathrm{pH}$ 감 소에 의한 준임상형 및 임상형 산독증과 부제 엽에 의해 젖소의 생산성이 감소할 수 있다. Lammers 등(1996)이 조사료와 TMR의 입자도 를 측정하는 새로운 방법을 개발하기 위하여 미국 북동부 지역에 있는 8개 주(州 고부터 채 취한 26 개의 $\mathrm{TMR}$ 샘플을 분석한 결과 중간 체(8 $7 \mathrm{~mm})$ 에 남아 있는 입자에 해당되는 것 이 $90 \%$ 이상을 차지하고 있는 것과 비교해보 면 국내의 TMR은 사료의 물리성에 많은 문제 점이 있음을 알 수 있다. 이러한 조사결과로 국내에서 이용되고 있는 TMR, 특히 유통 TMR 에서 입자도의 분포가 고르게 분포되지 못하고 $19 \mathrm{~mm}$ 보다 크거나 $8 \mathrm{~mm}$ 보다 적은 양쪽 방향으 로 분포되어 있음을 알 수 있다. 따라서 이러 한 부분은 국내에서 사용하는 조사료 종류 및
조:농비율 등을 고려하여 현재 국내에서 생산 되는 다양한 종류의 유통 $\mathrm{TMR}$ 에 대한 적정 조사료 길이 기준제시를 위한 보다 많은 연구 가 있어야 할 것으로 사료된다.

$$
\text { IV 요 약 }
$$

본 시험은 자가제조 $\mathrm{TMR}$ 농가의 TMR 배합 기 운용실태와 국내에서 생산 이용되고 있는 $\mathrm{TMR}$ 을 대상으로 TMR 배합소에서 생산되는 20개 유통 TMR과 농가에서 직접 제조하여 이 용하는 20개 자가 TMR의 입자도를 Penn State Particle Size Separator를 이용하여 측정하여 $\mathrm{TMR}$ 입자도의 분포를 측정한 결과, 자가 TMR 배합기를 이용하여 TMR을 제조하는 농 가의 1 일 총 배합에 소요되는 시간은 $48.6 \pm$ 28.0분으로 나타났으며, 자가 TMR 농가의 보 유 배합기 형태는 2오거가 55.5\%로 가장 많았 고, 여름철 및 다른 계절에 1일 2회 배합하는 농가가 44.4 및 $22.2 \%$ 였다. 자가 TMR 농가의 배합기 가동시간별 상위 체에 남아 있는 비율 이 21.5 $5.6 \%$, 중간 체에 남아 있는 비율이 $16.0 \sim 5 \%$ 그리고 바닥 체에 남은 사료의 비 율은 52.8 1.4\%로 많은 차이가 있었다. 자가 및 유통 $\mathrm{TMR}$ 의 입자 길이가 $19 \mathrm{~mm}$ 이상인 사 료의 비율이 각각 $24.9 \pm 1.4$ 및 $26.2 \pm 1.7 \%$, 입 자 길이가 8 $\exists \mathrm{mm}$ 미만인 사료의 비율이 각 
각 $22.8 \pm 1.0$ 및 $12.8 \pm 1.2 \%$ 그리고 입자 길이

가 $8 \mathrm{~mm}$ 미만인 사료의 비율이 $52.3 \pm 1.7$ 및 $61.0 \pm 1.5 \%$ 였다. 이는 자가 TMR과 유통 TMR 모두에서 8 $7 \mathrm{~mm}$ 미만 범위에 있는 입자는 Penn State Separator에서 추천하는 비율보다 각 각 $82.6 \%, 100 \%$ 가 낮은 것으로 나타났는데, 이 는 전체적으로 국내에서 생산 이용되고 있는 $\mathrm{TMR}$ 의 입자도가 긴 것과 짧은 것의 적절한 조화가 이루어지지 않고 있음을 알 수 있다. 따라서 $\mathrm{TMR}$ 을 급여하고 있는 농가에서 $\mathrm{TMR}$ 중 입자도가 적정한지를 평가하기 위한 가장 기본적인 일은 우군의 반추행동을 모니터링하 는 일이다. 즉, 전체 우군중 사료를 섭취하고 있는 소를 제외하고 휴식중에 있는 소들중 반 추를 하고 있는 소가 $40 \%$ 가 안된다면 전체적 으로 입자도가 너무 적거나 조사료의 비율이 너무 낮지 않은지 검토하여 배합시간을 조정하 거나 배합비를 재조정해 주어야 할 것이다.

\section{$\mathrm{V}$ 인 용 문 헌}

1. Duncan, D. B. 1955. Multiple range and multiple F test. Biometerics. 11:142.

2. Fahey, G. C. and Berger, L. L. 1988. Carbohydrate nutrition of ruminants. Page 269 in The Ruminant Animal: Digestive Physiology and Nutrition. D. C. Church, ed. Prentice-Hall, Englewood Cliffs, NJ.

3. Grant, R. J., Colenbrander, V. F. and Mertens, D. R. 1990. Milk fat depression in dairy cows: role of particle size of alfalfa hay. J. Dairy Sci. 73:1823.

4. Jaster, E. H. and Murphy, M. R. 1983. Effects of varying particle size of forage on digestion and chewing behavior of dairy heifers. J. Dairy Sci. 66:802.

5. Jud Heinrichs. 1996. Evaluating particle size of forages and TMRs using the Penn State Particle Size Separator. www.das.psu.edu/dcn/catforg/particle/

6. Linn, J. G. Management of TMR feeding programs. Feeding Total Mixed Rations to Dairy Cattle. Management of TMR feeding programs. 1995. U. S. Feeding Grains Council.

7. Lammers, B. P., Buckmaster, D. R. and Heinrichs, A. J. 1996. A simple method for the analysis of particle size of forage and total mixed rations. J. Dairy Sci. 79:922.

8. Martz, F. A. and Belyea, R. L. 1986. Role of particle size and forage quality in digestion and passage by cattle and sheep. J Dairy Sci. 69:1996.

9. National Research Council. 1989. Nutrient Requirements of Dairy Cattle. 6th Rev. Ed. Natl. Acad. Sci., Washington, DC.

10. Santini, F. J., Hardie, A. R., Jorgensen, N. A. and Finner, M. F. 1983. Proposed use of adjusted intake based on forage particle length for calculation of roughage indexes. J. Dairy Sci. 66:811.

11. SAS. SAS/STAT. Software for PC, SAS/STAT user's guide : Statistics. SAS inst., Cary, NC(1997).

12. Shaver, R. D. 1990. Forage particle length in dairy rations. Page 58 in Proc. Dairy Feeding Systems Symp. Northeast Reg. Agric. Eng. Service, Harrisburg, PA.

13. Smith, T. R. and Pritchard, D. E. 1983. An overview of. recent developments in individual concentrate feeding equipment and management. Page 150 in Proc. Second NatI. Dairy Housing Conf. Am. Soc. Agric. Eng., St. Joseph, MI.

14. Sudweeks, E. M., Ely, L. 0., Mertens, D. R. and Sisk, L. R. 1981. Assessing minimum amounts and form of roughages in ruminant diets: roughage value index system. J. Anim. Sci. 53:1406.

15. Uden, P. 1987. The effect of grinding and pelleting hay on digestibility, fermentation rate, digesta passage and rumen and faecal particle size in cows. Anim. Feed Sci. Technol. 19:145.

16. Weston, R. H. and Kennedy, P. M. 1984. Various aspects of reticulorumen digestive function in relation to diet and digests particle size. Page 1 in Proc. Techniques in Particle Size Analysis of Feed and Digesta in Ruminants. P. M. Kennedy, ed. Can. Soc. Anim. Sci., Edmonton, AB, Canada.

17. Woodford, J. A., Jorgensen, N. A. and Barrington, G. P. 1986. Impact of dietary fiber and physical form on performance of lactating cows. J. Dairy Sci. 69:1035.

18. Woodford, S. T. and Murphy, M. R. 1988. Effect of forage physical form on chewing activity, dry matter intake, and rumen function of dairy cows in early lactation. J. Dairy Sci. 71:674.

(접수일자 : 2003. 5. 9. / 채택일자 : 2003. 7. 3.) 